\title{
Evaluation of the Restoration Success of Endodontic Therapy of the Primary Molars
}

\author{
Zuhal Kirzioglua \\ Ozge Erken Gungor ${ }^{b}$ \\ Z. Zahit Ciftcic
}

\begin{abstract}
Objectives: The aim of this study was to evaluate the clinical and radiographic success rates of pulpotomized primary molar teeth restored with a compomer material with using United States Public Health Service (USPHS) criteria.

Methods: In 173 primary molars of 156 child patients, aged within 4-9 years (mean age: 6.1 1.4 years), conventional pulpotomy treatment were performed. The teeth treated using calcium hydroxide, formocresol or ferric sulphate. After pulpotomy procedure, teeth were restored with compomer material. The teeth were evaluated as clinically and radiographically during a period of 12-24 months. Both of success of pulpotomy treatment and also restorative material (compomer material) were evaluated during follow-up period. The data were assessed with chi-square test.

Results: At the end of the first year, $45 \%$ of initial treated teeth were checked, but only $18 \%$ were checked at the end of the second year. The first year success rates in the groups treated with $\mathrm{CH}$, FC, and FS were $87.5 \%, 95 \%$, and $79 \%$, respectively, and, as the number of controllable patients was lower, the success rates on available teeth were determined to be $88.3 \%$ and $80 \%$, respectively, according to the materials at the end of the second year. Restorations having been made, they were analyzed in accordance with USPHS criteria.

Conclusions: At the end of the first year, $67.5 \%$ of compomer restorations were detected to be original and healthy and at the end of the second year, $57 \%$ were deemed healthy. No statistically significant relationships were found between marginal adaptation, secondary caries and pulpotomy success (chi-square test, $P>$.05). Among the three groups, there is no significant difference in terms of success. The least successful age group was defined as 4-6 years. (Eur J Dent 2011;5:415-422)
\end{abstract}

Key words: Primary molar; Endodontic therapy; Success rate; Pulpotomy.

a Professor, Suleyman Demirel University, Faculty of Dentistry, Department of Paediatric Dentistry, Isparta, Turkey.

b Assistant Professor, Akdeniz University, Faculty of Dentistry, Department of Paediatric Dentistry, Antalya, Turkey.

Research Assistant, Suleyman Demirel University, Faculty of Dentistry, Department of Paediatric Dentistry, Isparta, Turkey.

- Corresponding author: Ozge Erken Gungor Akdeniz Universitesi Dishekimligi Fakultesi Pedodonti A.D. Antalya, Turkey.

Phone: +902423106965

Fax: +902423106967

E-mail: erkentrayahoo.com

\section{INTRODUCTION}

Pulpotomy, or the surgical amputation of affected coronal pulp, is generally preferred among various endodontic therapies on primary teeth due to its easy application and its rate of success. ${ }^{1,2}$

Individual factors such as age, stage of root formation, whether the tooth is to be functional or not, and periodontal condition, as well as therapy factors such as the size of pulp exposure, cause of exposure, microbial contamination of the operation area, and material that is used for pulpotomy affect the success of the treatment procedure. ${ }^{3,4}$ 
Researchers continue to search for a new pulpotomy material that is harmless to remaining pulp and surrounding tissue that will promote healing of radicular pulp without hindering physiological root resorption, and be bactericidal. ${ }^{5-7}$ Different materials have been used for pulpotomy treatment, some of which are formocresol (FC), calcium hydroxide $(\mathrm{CH})$, ferric sulfate (FS), gluteraldehyde, mineral trioxide aggregate (MTA), and bioactive glass (BAG). Among these, FC is the most frequently used agent in pulpotomy procedures on primary molars because it is easy to implement, has a high success rate and a low cost, and is bactericidal. ${ }^{1}$ However, concerns about the safety of FC have been increasing due to its immunologic and mutagenic side effects. $5,8,9$ Because of this, the use of new materials in primary tooth pulpotomy has been evaluated. ${ }^{6,10}$ Although $\mathrm{CH}$ has been recommended as an alternative to $F C$, its greatest disadvantage is that it causes internal root resorption. ${ }^{6}$ FS is used as a haemostatic agent during the pulpotomy procedure and is shown to have similar clinical/radiographic success to FC. 2,6 MTA is another pulpotomy agent which has some disadvantages, such as long hardening reaction time and high cost. $3,6,11-14$

In the literature concerning this matter, although FS had similar success rates as FC, $\mathrm{CH}$ showed lower success rates. In these studies, follow-up with the patients was conducted at periods between six months and two years. 5,11,15

Stainless steel crowns (SSC), amalgam, composite, and compomer materials are used as restorative material on the pulpotomized primary tooth. 1,5,8,16-21 There are studies which examine different restorative materials used with the same pulpotomy material, ${ }^{22,23}$ but there are no studies which examine different pulpotomy materials used with same kind of restorative materials success rates.

The aim of this study was to evaluate the effects of compomer materials on pulpotomy success and to relate clinical and radiographic findings of pulpotomy treatment and compomer restoration during a period of 12-24 months. United States Public Health Service (USPHS) criteria for compomer materials were used for evaluating marginal adaptation, secondary caries, color adaptation, marginal discoloration and anatomic form. ${ }^{24}$

\section{MATERIALS AND METHODS}

The study sample consisted of children aged 4-9 years (mean age: 6.1 \pm 1.4 years) selected from patients who visited Süleyman Demirel University, Faculty of Dentistry Department of Pediatric Dentistry in Isparta, Turkey. All children were healthy and cooperative, had normal occlusion, had none of their primary molars extracted, had a Simplified Oral Hygiene Index (OHI-S) level of 1. Before the treatment, the children's parents signed letters of informed consent. One hundred seventy-three primary molars from 156 child patients were used to perform pulpotomy treatment in our study. The clinical selection criteria for the teeth that were included in the study was as follows: the tooth was at function, caries cavity was two-faced, no infraposition of the teeth, no tenderness to percussion and palpation, no history of spontaneous and nocturnal pain, no pathological mobility, no abscess formation, and no color change in teeth except caries. The radiographic selection criteria was as follows: healthy lamina dura and visible periodontal space, permanent teeth germ present at the normal position, at least two-thirds of the root length was present, no internal resorption, no lesion at interradicular or periapical space, and no pulpal calcification.

After the administration of local anesthesia, the selected teeth were isolated with a rubber dam. The coronal pulp was removed and the hemorrhage was controlled a time that was determined according to pulpotomy agent kind, then amputation materials were applied.

In the $\mathrm{CH}$ group (Group A), the canal orifices were dressed with aqueous $\mathrm{Ca}(\mathrm{OH})_{2}$ obtained by mixing a calcium hydroxide powder (Kalsin/Aktu, Izmir, Turkeyl with sterile saline; in the FC group (Group B), FC (Sultan, Turkey) was diluted in a $5: 1$ ratio (Buckley's formula); and in the FS group (Group C), a solution of $20 \%$ FS (Visco Stat, Ultradent, South Jordan) was placed on the amputated pulp. In groups, ZOE and polycarboxylate cement was placed directly on the radicular pulpal stumps and in the coronal pulp space, and the tooth was restored with compomer (Dyract, Dentsply, Germanyl in the same session.

The children were recalled for clinical and radiographic examinations at six-month intervals. Clinically, teeth that exhibited no color change at gingiva, pathological mobility, tenderness to per- 
cussion and palpation, swelling, fistulization, or lymphadenopathy at corresponding region; and radiographically, teeth that exhibited no evidence of periradicular radiolucency, no internal root resorption, no root canal calcification, and had normal physiologic root resorption were judged successful. Treatments were statistically evaluated according to the success of the pulpotomy, the success of restorations which were evaluated with USPHS criteria, and the relationship between restoration success and success of the pulpotomy treatment. Statistical analysis of the differences in treatment outcomes was performed by using the chi-square test.

\section{RESULTS}

It was found that the $68 \%$ of the teeth on which pulpotomy treatment initially applied were mandibular primary molars.

It can be seen that approximately $36 \%$ of initial patients at the end of the first year had controllable teeth (the teeth that the patients who could come to control appointment), but only $16 \%$ at the end of the second year. At the end of the first year, whereas 70 teeth in 56 patients were being controlled, at the end of the second year this number decreased to 28 teeth in 25 patients (Figure 1). The distribution of controllable teeth at the end of the first and second years according to group is shown in Figure 2.

At the end of the first year, internal resorption was seen in 9 teeth total: 4 in A group, 1 in B group, and 4 in $C$ group. At the end of the second year, internal resorption was seen in 4 teeth total: 2 in A group, and 2 in B group. These teeth were accepted as failures, but their clinical follow-up was decided by researchers. At the end of the second year, the number of patients in $C$ group coming to their control appointments was not statistically sufficient to form a group.

The first year success rates in the groups treated with $\mathrm{CH}, \mathrm{FC}$, and $\mathrm{FS}$ were $87.5 \%, 95 \%$, and $79 \%$, respectively, and, as the number of controllable patients was lower, the success rates on available teeth were determined to be $88.3 \%$ and $80 \%$, respectively, according to the materials. Approximately $81.4 \%$ of the 70 controllable teeth were seen to be successful.

At the end of the first year, whereas root canal calcification was seen in $34.3 \%, 47.3 \%$ and $42.1 \%$, respectively, of the groups treated with $\mathrm{CH}, \mathrm{FC}$, and $\mathrm{FS}$, at the end of the second year, depending on the decrease in the number of patients (All of the patients did not come to control the second year), this rate was $47 \%$ in $\mathrm{CH}$ group, but it decreased to $40 \%$ in $\mathrm{FC}$ group.

Restorations were analyzed in accordance with USPHS criteria and it was determined that, at the end of the first and second years, the marginal adaptation of $64.3 \%$ and $60.8 \%$ of the controllable restorations, respectively, was Alpha (no fracture on restoration margin), $24.3 \%$ and $21.5 \%$ was Bravo lan available visible crevice on restoration margin), and $11.5 \%$ and $17.8 \%$ was Charlie (explorer catches in a visible crevice between the tooth and restoration but the base is intact). At the end of the first year, secondary caries were observed in $12.8 \%$ of the restorations, but they were seen in $17.8 \%$ of the restorations at the end of the second year.

No significant statistical (chi-square test) relationship was found among marginal adaptation, secondary caries, and the success of pulpotomy $(P>.05)$ (Figure 3). At the end of the first year, in $A, B$, and C groups, respectively, $90 \%, 91 \%$, and $78 \%$ of the restorations for which the marginal adaptation is Alpha; $78 \%, 100 \%$, and $80 \%$ of the restorations for which the marginal adaptation is Bravo; and $75 \%$ and $50 \%$ of the restorations for which the marginal adaptation is Charlie were determined to be successful (no Charlie score could be obtained in group $\mathrm{C}$ ). On the other hand, at the end of the second year, depending on the decrease in the number of controllable patients, these values changed. According to this, in groups $A$ and B, $100 \%$ and $86 \%$ of the restorations for which the marginal adaptation is Alpha, $60 \%$ and $100 \%$ of the restorations for which the marginal adaptation is Bravo, and $67 \%$ and $50 \%$ of the restorations for which the marginal adaptation is Charlie were determined to be successful (Figure 4). Other features of the restorations, such as color adaptation, marginal discoloration, and anatomic form, were evaluated in accordance with USPHS criteria and it was determined that, in the first and second years, $85 \%, 78.5 \%, 73 \%, 68 \%$, and $77 \%, 75 \%$ Alpha scores were gained, respectively (Figure 5).

Among the three groups, there is no significant difference in terms of success. The least successful age group was 4-6 years. No statistically sig- 
nificant relationship was found between marginal adaptation, secondary caries, and success of pulpotomy $(P>$.05).

\section{DISCUSSION}

Of the many endodontic treatments allowing decay primary teeth to remain in the mouth healthy until they complete their physiological root resorptions, pulpotomy is one of the treatment methods that can be applied with different materials that possess various protective charac-

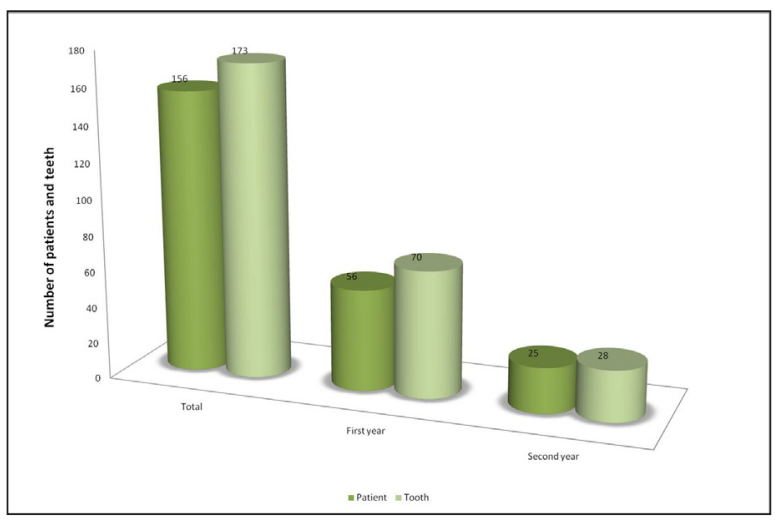

Figure 1. The number of controllable teeth and patients at the end of first and second years.

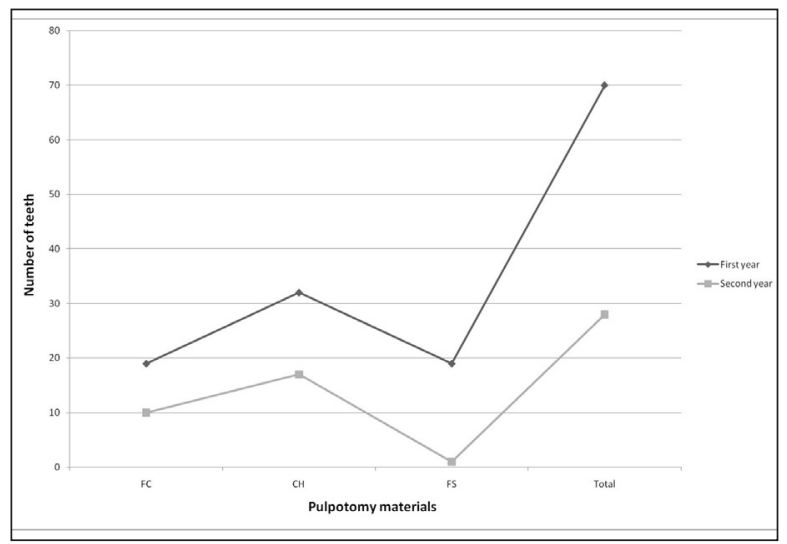

Figure 2. The distribution of the controllable teeth according to the groups, at the end of the first and second years.

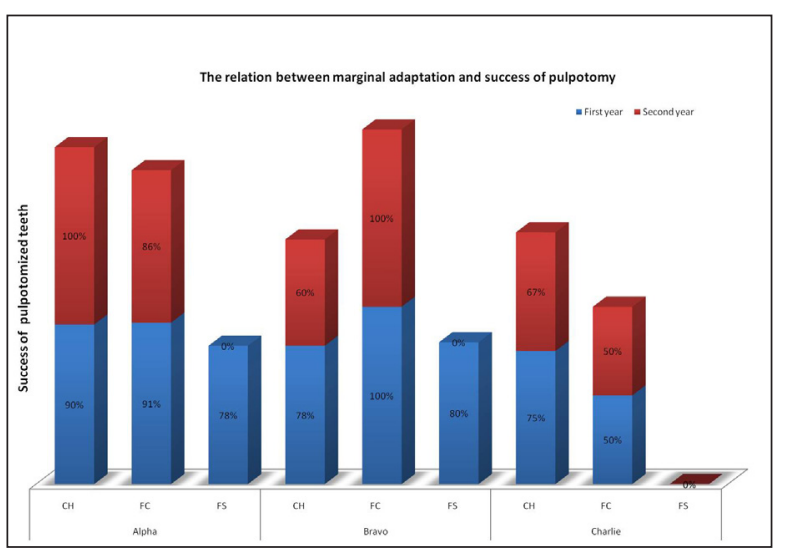

Figure 4. The relation between marginal adaptation and success of pulpotomy according to treatment groups at the end of first and second years. teristics. Many variable factors affect the success of the treatment and, depending on these factors, difficulties may occur in the long-term. This is why long-term follow-up in studies is valuable in terms of enlightening other researches. At the beginning of our research, 156 children-patients were grouped so as to be age homogeneous, but homogeneity was disturbed as the number of controllable patients decreased.

The choice of restoration materials is an important factor in increasing the success of pulpotomy treatment. Amalgam, SSC, and adhesive resin materials are used as coronal restorative materials in pulpotomy treatments. ${ }^{16-19,25,26}$ SSC was known to be an ideal restorative material in pulpotomy treatments, and, especially when it was used in the same session with pulpotomy treatment, it was observed to increase the success significantly. ${ }^{27}$ Compared to a research study of successful pulpotomy treatments where coronal restorations were made by amalgam and SSC, the success rate of amalgam in the current study was found to be lower. ${ }^{28}$ Today, adhesive materi-



Figure 3. The state of the marginal adaptation and secondary caries according to pulpotomy materials at the end of first and second years.

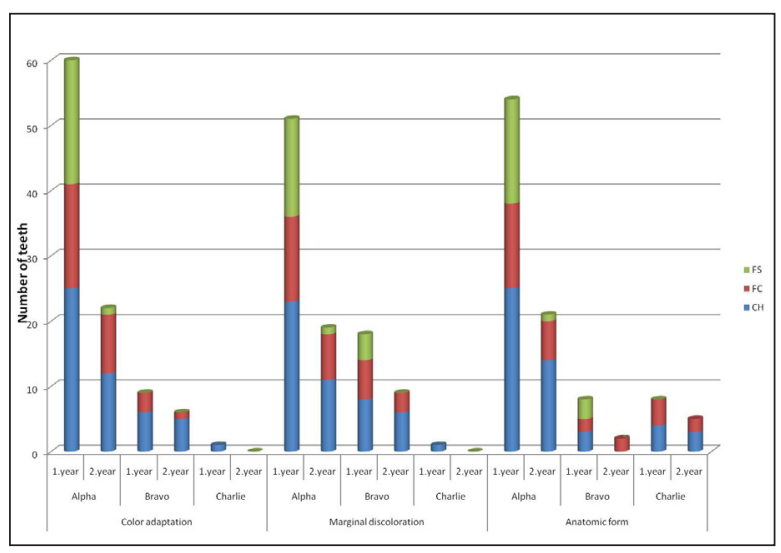

Figure 5. The state of the color adaptation, marginal discoloration and anatomic form according to pulpotomy materials at the end of first and second years. 
als and compomer materials are commonly used, particularly on primary teeth, and are preferred by patients, parents, and dentists.

In our research, compomer was used as a restorative material, because it is easy to implement and often used in primary molars. In reviewing the literature concerning treatments that use different pulpotomy materials, there was no research found that used compomer as the restorative material where the restoration was evaluated in accordance with USPHS criteria.

In the current study, at the end of the first year, 23 of 29 restorations for which the marginal adaptation score is Alpha, 9 of 11 restorations for which the marginal adaptation score is Bravo, and 2 of 3 restorations for which the marginal adaptation score is Charlie were successful. At the end of the second year, 15 of 16 restorations with the Alpha score, 5 of 6 restorations with the Bravo score, and 3 of 5 restorations with the Charlie score were successful. At the end of two years, pathological root resorption in 3 of the teeth in which the marginal adaptation is Alpha, periapical radiolucence in 3 , and root canal calcification in 1 of them were identified. The appearance of such pulpal responses without disturbing the marginal adaptation may occur due to the infection of the root pulp before pulpotomy treatment, the formation of calcified structures in the root pulp, and the later observation of resorptions. ${ }^{18}$ As the zinc oxide eugenol and polycarboxylate cement bases remain originally under restoration, no radiographically pathological situations were observed in 5 restorations for which the marginal adaptation score is Charlie, and these restorations were successful. At the end of the first year, $67.5 \%$ of compomer restorations were detected to be original and healthy, and at the end of the second year, $57 \%$ were deemed healthy. No statistically significant relationships were found between marginal adaptation and pulpotomy success ( $P>$.05).

In a study by Cehreli et al, ${ }^{22}$ in the pulpotomy treatments applied on primary molar teeth with FC, composite and compomer restoration was performed using coronal restoration materials and, at the end of 24 months, it was observed that marginal adaptation change and marginal discoloration were more common in compomer restorations. It was pointed out that the formaldehyde in FC may cause gingival problems, but it may also increase the attachment of adhesive materials to primary dentin. ${ }^{16,25}$ The probable reason why we gained a higher success rate in pulpotomies with FC than in other groups may be due to the formaldehyde in FC.

In Guelmann et al's research, ${ }^{23}$ pulpotomy treatment was applied on primary molar teeth and the teeth were restored with different materials. At the end of the study, it was shown that resinbased materials work better to protect marginal adaptation, SSC cemented with glass ionomer cement does not provide a hermetic obturation, and IRM restoration is not sufficient to prevent micro leakage. It was also shown that composite and compomer materials cannot eliminate the micro leakage completely, yet they provide a better marginal obturation than do traditional glass ionomer cements. ${ }^{29}$ In our study, more than half of compomer restoration was shown to be original and healthy at the end of two years.

When the relationship between the materials used and the age factor is assessed, it is determined that the failure rate was higher in the groups of 4-6-year-olds for all materials. This outcome is consistent with some studies in which patients who are 6 years old are shown to comprise the most unsuccessful age group. ${ }^{16,30}$ This can be explained by root resorption not being initiated, as well as the strong response of the pulp, yet in the studies, any difference between the teeth in which root resorption initiated and the ones in which root resorption did not initiate was not detected in terms of pulp response. ${ }^{31-33}$ That is why the failure in this period may depend on the difficulty obtaining isolation and the limited treatment time. In Guelmann et al's study, ${ }^{34}$ any difference was not indicated among the groups in terms of success.

Despite its toxic, mutagenic, and carcinogenic effects, the clinical success rate of FC increases from $68 \%$ to $100 \%$, and the radiographic success rate increases from $56 \%$ to $97 \%$. 516,18,25,35-37 In our research, FC showed a $95 \%$ success rate at the end of the first year, and an $80 \%$ success rate at the end of the second year.

Waterhouse et $\mathrm{al}^{37}$ applied pulpotomy treatment using $\mathrm{FC}$ and $\mathrm{CH}$ on 84 teeth from 52 children ranging between 3.3-12.5 years, and they showed an $84 \%$ success rate in the FC group and a $77 \%$ success rate in the $\mathrm{CH}$ group. In a study comparing the radiographic success of $\mathrm{FC}$ and $\mathrm{FS}$, it was 
shown that FC was $56 \%$ successful and FS was $43 \%$ successful. ${ }^{36} \mathrm{FS}$ had a similar success rate to FC in pulpotomy treatment. ${ }^{38}$ In a study comparing FC and FS pulpotomies, it was shown that the clinical success rate of FS was high (78\%-100), whereas the radiographic success rate was too changeable (42\%-97). ${ }^{15,39-41}$ In our research, the success rate of FS pulpotomies was shown to be $79 \%$. When FC and other methods are compared (electrosurgery, MTA), whereas FC is found to be more successful in one of the studies, ${ }^{10}$ no significant difference between the methods was found in other studies. ${ }^{8,10,17}$

Whereas $\mathrm{CH}$ has taken its place as a pulpotomy material since it does not create systemic toxicity, the fact that it causes internal root resorption creates problems for clinicians. ${ }^{6,19}$ In our research, at the end of the first year, equal internal resorptions were seen in pulpotomy treatments conducted using FS and $\mathrm{CH}$. The clinical and radiographic success rates of $\mathrm{CH}$ change between $31 \%$ and $100 \% .5,42,43$ In our research, $\mathrm{CH}$ showed an $87.5 \%$ success rate at the end of the first year, and an $88.3 \%$ success rate on controllable teeth at the end of the second year. In a research in which FC, $\mathrm{CH}$, and FS was used, it was found that FC showed the highest success rate, that of FS is close to that of $\mathrm{FC}$, and $\mathrm{CH}$ showed the lowest success rate. ${ }^{15}$

In a study by Eyüboḡlu et $\mathrm{al}^{16}{ }^{16}$ in pulpotomy treatment using $\mathrm{FC}, \mathrm{CH}, \mathrm{FS}$, and MTA on primary molars of children ranging between 6-8 years, SSC was used as a coronal restorative material. While there was no statistically significant difference among materials, the study showed that FS was the most clinically successful material and MTA was the most radiographically successful one. In this study, where pulpotomy treatments are assessed histologically as well, when the dentin bridge formation and the root canal calcification were examined, it was detected that the radiological and histological results were not consistent with each other. Working with the same materials, Sönmez et al ${ }^{5}$ used amalgam as the coronal filling in the same session, and indicated success rates of $76.9 \%, 46.1 \%, 73.3 \%$ and $66.6 \%$, respectively, at the end of 24 months.

It is known that SSC increases success in primary endodontic treatments. However, due to the aesthetic preferences of the patients and their parents, the usage of compomer material has increased. This is why, in our research, we used compomer material; it was determined that compomer restoration success did not affect the success of pulpotomy treatment in each of the three groups. The basic material providing a hermetic obturation under restoration is also one of the important factors in increasing success. The reasons why we obtained similar results are that treatment indication was decided truly and the treatment was conducted by experienced pediatric dentists.

\section{CONCLUSIONS}

At the end of the first year, $67.5 \%$ of compomer restorations were detected to be original and healthy and at the end of the second year, 57\% were deemed healthy. No statistically significant relationships were found between marginal adaptation, secondary caries and pulpotomy success. However, FC appeared to be most appropriate pulpotomy agent than $\mathrm{CH}$ and $\mathrm{FS}$ when a one-year results of marginal adaptation was compared. But, at the end of the second year, $\mathrm{CH}$ appeared to be more successful pulpotomy agent among the others. Among the three groups, there is no significant difference in terms of success. The least successful age group was defined as $4-6$ years.

\section{REFERENCES}

1. Salako N, Joseph B, Ritwik P, Salonen J, John P, Junaid TA. Comparison of bioactive glass, mineral trioxide aggregate, ferric sulfate, and formocresol as pulpotomy agents in rat molar. Dent Traumatol 2003;19:314-320.

2. Ingle JI, Bakland LK. Endodontics. 5th edition. Canada: BC Decker Inc. 2002.

3. Cohen ST, Burns R. Patways of the pulp. 6th edition. St.Louis: Mosby 1994.

4. Menezes R, Bramante CM, Letra A, Carvalho VG, Garcia RB. Histologic evaluation of pulpotomies in dog using two types of mineral trioxide aggregate and regular and white Portland cements as wound dressings. Oral Surg Oral Med Oral Pathol Oral Radiol Endod 2004;98:376-379.

5. Sonmez D, Sari S, Cetinbas T. A Comparison of four pulpotomy techniques in primary molars: a long-term followup. J Endod 2008;34:950-955.

6. Srinivasan V, Patchett CL, Waterhouse PJ. Is there life after Buckley's Formocresol? Part I -- a narrative review of alternative interventions and materials. Int J Paediatr Dent 2006;16:117-127.

7. Pinkham JR. Pediatric Dentistry Infancy Through Adolescence. 3rd edition. USA: W.B. Saunders Company, 1999. 
8. Bahrololoomi Z, Moeintaghavi A, Emtiazi M, Hosseini G. Clinical and radiographic comparison of primary molars after formocresol and electrosurgical pulpotomy: a randomized clinical trial. Indian J Dent Res 2008;19:219-223.

9. Zarzar PA, Rosenblatt A, Takahashi CS, Takeuchi PL, Costa Junior LA. Formocresol mutagenicity following primary tooth pulp therapy: an in vivo study. J Dent 2003;31:479485.

10. Saltzman B, Sigal M, Clokie C, Rukavina J, Titley K, Kulkarni GV. Assessment of a novel alternative to conventional formocresol-zinc oxide eugenol pulpotomy for the treatment of pulpally involved human primary teeth: diode laser-mineral trioxide aggregate pulpotomy. Int J Paediatr Dent 2005; 15:437-447.

11. Naik S, Hegde AM. Mineral trioxide aggregate as a pulpotomy agent in primary molars: An in vivo study. $J$ Indian Soc Pedod Prev Dent 2005;23:13-16.

12. Aeinehchi M, Eslami B, Ghanbariha M, Saffar AS. Mineral trioxide aggregate (MTA) and calcium hydroxide as pulpcapping agents in human teeth: a preliminary report. Int Endod J 2003;36:225-231.

13. Moretti AB, Oliveira TM, Sakai VT, Santos CF, Machado MA, Abdo RC. Mineral trioxide aggregate pulpotomy of a primary second molar in a patient with agenesis of the permanent successor. Int Endod J 2007;40:738-745.

14. Camilleri J, Pitt Ford TR. Mineral trioxide aggregate: a review of the constituents and biological properties of the material. Int Endod J 2006;39:747-754.

15. Markovic D, Zivojinovic V, Vucetic M. Evaluation of three pulpotomy medicaments in primary teeth. Eur J Paediatr Dent 2005;6:133-138.

16. Eyüboḡlu Ö. Clinic, radiographic and histological evaluation of primary teeth pulpotomies using different pulpotomy materials. Atatürk University, Institute of Health Science, 2007

17. Dean JA, Mack RB, Fulkerson BT, Sanders BJ. Comparison of electrosurgical and formocresol pulpotomy procedures in children. Int J Paediatr Dent 2002;12:177-182.

18. Waterhouse PJ, Nunn JH, Whitworth JM, Soames JV. Primary molar pulp therapy--histological evaluation of failure. Int J Paediatr Dent 2000;10:313-321.

19. Sonmez D, Duruturk L. $\mathrm{Ca}(\mathrm{OH})_{2}$ pulpotomy in primary teeth. Part I: internal resorption as a complication following pulpotomy. Oral Surg Oral Med Oral Pathol Oral Radiol Endod 2008; 106:e94-98.

20. Kindelan SA, Day P, Nichol R, Willmott N, Fayle SA. UK National Clinical Guidelines in Paediatric Dentistry: stainless steel preformed crowns for primary molars. Int J Paediatr Dent 2008;18 Suppl 1:20-28.
21. Kramer N, Frankenberger R. Compomers in restorative therapy of children: a literature review. Int J Paediatr Dent 2007;17:2-9.

22. Cehreli ZC, Cetinguc A, Cengiz SB, Altay AN. Clinical performance of pulpotomized primary molars restored with resin-based materials. 24-month results. Am J Dent $2006 ; 19: 262-266$.

23. Guelmann M, Bookmyer KL, Villalta P, Garcia-Godoy F. Microleakage of restorative techniques for pulpotomized primary molars. J Dent Child (Chic) 2004;71:209-211.

24. Pascon FM, Kantovitz KR, Caldo-Teixeira AS, Borges AF, Silva TN, Puppin-Rontani RM, Garcia-Godoy F. Clinical evaluation of composite and compomer restorations in primary teeth: 24-month results. J Dent 2006;34:381-388.

25. Holan G, Fuks AB, Ketlz N. Success rate of formocresol pulpotomy in primary molars restored with stainless steel crown vs amalgam. Pediatr Dent 2002;24:212-216.

26. Holan G, Eidelman E, Fuks AB. Long-term evaluation of pulpotomy in primary molars using mineral trioxide aggregate or formocresol. Pediatr Dent 2005;27:129-136.

27. Guelmann M, Fair J, Turner C, Courts FJ. The success of emergency pulpotomies in primary molars. Pediatr Dent 2002;24:217-220.

28. Gruythuysen RJ, Weerheijm KL. Calcium hydroxide pulpotomy with a light-cured cavity-sealing material after two years. ASDC J Dent Child 1997;64:251-253.

29. Xie H, Zhang F, Wu Y, Chen C, Liu W. Dentine bond strength and microleakage of flowable composite, compomer and glass ionomer cement. Aust Dent J 2008;53:325-331.

30. Boeve C, Dermaut L. Formocresol pulpotomy in primary molars: a long term radiographic evaluation. J Dent Child 1982;49:191-196.

31. Sarı \$. In vitro and in vivo evaluation of the effects of rootcanal resorption on endodontic procedures in primary teeth. Ankara University, Institute of Health Science, 1997.

32. Sari S, Aras S, Gunhan 0. The effect of physiological root resorption on repair potential of primary tooth pulp. J Clin Pediatr Dent 1999;23:227-233.

33. Sari S, Aras S, Gunhan 0. The effect of physiological root resorption on the histological structure of primary tooth pulp. J Clin Pediatr Dent 1999;23:221-225.

34. Guelmann M, Mcllwain MF, Primosch RE. Radiographic assessment of primary molar pulpotomies restored with resin-based materials. Pediatr Dent 2005;27:24-27.

35. Fuks $A B$, Bimstein E. Clinical evaluation of diluted formocresol pulpotomies in primary teeth of school children. Pediatr Dent 1981;3:321-324.

36. Vargas KG, Packham B. Radiographic success of ferric sulfate and formocresol pulpotomies in relation to early exfoliation. Pediatr Dent 2005;27:233-237. 
37. Waterhouse PJ, Nunn JH, Whitworth JM. An investigation of the relative efficacy of Buckley's Formocresol and calcium hydroxide in primary molar vital pulp therapy. Br Dent J 2000;188:32-36.

38. Ranly DM, Godoy FG. Current and potential pulp therapies for primary and young permanent teeth. $J$ Dent 2000;28:153-161.

39. Peng L, Ye L, Guo X, Tan H, Zhou X, Wang C, Li R. Evaluation of formocresol versus ferric sulphate primary molar pulpotomy: a systematic review and meta-analysis. Int Endod J 2007; 40:751-757.

40. Huth KC, Paschos E, Hajek-Al-Khatar N, Hollweck R, Crispin A, Hickel R, Folwaczny M. Effectiveness of 4 pulpotomy techniques--randomized controlled trial. J Dent Res 2005;84:1144-1148.

41. Casas MJ, Kenny DJ, Johnston DH, Judd PL. Long-term outcomes of primary molar ferric sulfate pulpotomy and root canal therapy. Pediatr Dent 2004;26:44-48.

42. Moretti AB, Sakai VT, Oliveira TM, Fornetti AP, Santos CF, Machado MA, Abdo RC. The effectiveness of mineral trioxide aggregate, calcium hydroxide and formocresol for pulpotomies in primary teeth. Int Endod $J$ 2008;41:547-555.

43. Waterhouse PJ. Formocresol and alternative primary molar pulpotomy medicaments: a review. Endod Dent Traumatol 1995;11:157-162. 